\title{
Edible Rhus tripartita fruit as source of health-promoting compounds: characterization of bioactive components and antioxidant properties
}

\author{
Imen Abcha ${ }^{1,2} \cdot$ Paula Criado $^{2} \cdot$ Stephane Salmieri ${ }^{2} \cdot$ Hanen Najjaa ${ }^{2} \cdot$ Hiroko Isoda $^{3} \cdot$ Mohamed Neffati $^{1}$. \\ Monique Lacroix ${ }^{2}$
}

Received: 21 June 2019 / Accepted: 14 September 2019

(c) Crown 2019

\begin{abstract}
The fruits of Rhus tripartita had recently attracted great attention due to its notable therapeutic effects. Their potential effects are attributed to the richness of diverse classes of secondary metabolites. The objective of this research was to access the determination of chemical composition and antioxidant properties of $R$. tripartita fruit extracts and its partitioned fractions (absolute petroleum ether, 70\% aqueous ethanol, absolute ethyl acetate and water). LC-ESI-MS/MS and FTIR-ATR were used to assess the potential of $R$. tripartita fruits as a source of health-promoting constituents. A total of 38 phenolics, including flavones, flavonols, flavanones, organic acids, hydroxycinnamic acids and hydroxybenzoic acids, 26 of them were reported for the first time in $R$. tripartita. The main compounds were apigenin7-O-glucoside, apigenin and $p$-coumaric acid. The FTIR-ATR analysis results revealed the presence of characteristic functional groups such as $-\mathrm{OH}, \mathrm{C}-\mathrm{O},-\mathrm{C}=\mathrm{C}$ and $\mathrm{C}-\mathrm{H}$ of phenolic compounds, carboxylic acids, carbohydrates, lipophilic components and proteins in $R$. tripartita fruits. Furthermore, the ethyl acetate fraction showed the highest level of phenolic contents and strong antioxidant activities. The present study recommends $R$. tripartita fruits as source of natural antioxidants which can be used as bioactive ingredient for functional foods and nutraceuticals.
\end{abstract}

Keywords Rhus tripartita fruit · Antioxidants · LC-MS/MS · FTIR · Phenolic compounds

\section{Introduction}

Phenolic compounds have attracted a great interest in both pharmaceutical and food industries because of their health benefits [1]. Previous studies revealed that consumption of foods containing phenolic compounds can decrease the risk of human disease such as cancer, inflammation, immune and cardiovascular diseases [2]. Moreover, phenolic compounds

Monique Lacroix

monique.lacroix@iaf.inrs.ca

1 Pastoral Ecosystems and Valorization of Spontaneous Plants Laboratory, Tunisia Institute of Arid Land, Medenine 4119, Tunisia

2 INRS-Institut Armand-Frappier, Research Laboratories in Sciences Applied to Food, Institut of Nutraceutical and Functional Foods, Canadian Irradiation Centre, 531 des Prairies, Blvd., Laval, QC H7V 1B7, Canada

3 Alliance for Research on North Africa (ARENA), University of Tsukuba, 1-1-1 Tennoudai, Tsukuba, Ibaraki 305-8572, Japan have considerable antioxidant activity [3].These compounds could be regarded as the major determinant of antioxidant potentials of functional foods [4].

Recently, many studies indicate that medicinal and aromatic plants, rich in phenolic compounds, are good exogenous candidates for providing natural antioxidant which can replace the synthetic components [5]. In this order, wild edible and lesser-known plant species have received more attention as a natural source of antioxidant substances, with the Rhus tripartita (Anacardiaceae) an interesting example [7]. $R$. tripartita, locally known as 'Jdari', is a native preSaharan Tunisian plant. In vitro, in vivo and epidemiological studies have proven that $R$. tripartita exhibits biological functions toward some human diseases [9]. It has been used by Tunisians in herbal treatments for many diseases, such as diarrhea and dysentery. The extracts derived from this plant inhibit the growth of pathogenic bacteria in vitro (Escherichia coli, Salmonella typhimurium, Salmonella argenosa and Staphylococcus aureus), making it useful food preservatives [10]. Many studies have reported other beneficial functions for R. tripartita on human health, such as antiulcerogenic 
[11], antimalarial [12], antioxidant, anti-inflammatory [9] and cardioprotective activities [13]. The cardioprotective activity was correlated with the antioxidant activity of $R$. tripartita extract [13]. Moreover, the extract of $R$. tripartita is a potent and selective inhibitor of the cyclooxygenase (Cox-2) with a strong inhibition of acetylcholinesterase showing that $R$. tripartita could be a source of natural prophylactic agents against neuroinflammatory diseases like Alzheimer's disease [14]. In vivo, the $R$. tripartita fruit extract exhibited excellent hepatoprotective and nephroprotective activities [15]. The fruit of this plant is consumed fresh or stored, soaked in sour milk, or added to water for its refreshing taste [7]. $R$. tripartita fruits are highly nutritious and rich in protein, oil and fatty acids [16]. In addition, $R$. tripartita fruits are good candidates for the development of new healthy food, due to their high content in phenolic compounds such as biflavonoids, isoflavonoids and flavones and in triterpenoids such as betulinic acid [7]. Betulinic acid was recently reported to be responsible for the protective effect of $R$. tripartita fruit extract against $\mathrm{CCl}_{4}$-induced hepatotoxicity and cisplatininduced nephrotoxicity in vivo [15]. Currently, the important level of flavones in $R$. tripartita fruit was shown to reduce isoproterenol (ISO)-induced cardiac injury [13]. Several biological activities of $R$. tripartita fruit have been attributed to the richness of phenolic compounds [15]. As a result, in recent years there is a growing interest in the extraction of phenolic compounds from edible $R$. tripartita fruit to be used in food, nutraceutical and pharmaceutical products [8].

The extraction of phenolic compounds from plant materials is the first step that must be carried out before performing a comprehensive analysis of individual phenolic compounds [17]. One of the most important factors affecting the extraction efficiency of these compounds and their consequent health benefits is the extraction solvent, because the quantity and quality of phenolic compounds extracted from plant materials are strongly dependent on the type of solvents [18]. Aqueous mixtures containing ethanol, methanol, and ethyl acetate have been used to extract phenolic compounds in fruits, vegetables and foodstuffs [1]. Aqueous ethanol has been generally found to be more efficient in extraction of total phenolic and flavonoids [1]. Ethyl acetate has been also reported to be an important solvent in extracting phenolic acids and flavonoids and its low boiling point makes it easy to separate from extracts [17]. Numerous studies on the choice of appropriate solvents for extracting phenolic content had been carried out on some medicinal plant extracts [19], but to the best of our knowledge, the use of different solvent systems to extract phenolic compounds from $R$. tripartita fruits has not been reported yet.

As part of our ongoing study of edible part of R.tripartita, we report here a detailed composition of $70 \%$ aqueous ethanolic extract and ethyl acetate fraction obtained from fruits by HPLC-ESI-DAD-MS-MS. Further, we examined the variations in functional groups of bioactive compounds of extracts and fractions (absolute petroleum ether, 70\% ethanol, absolute ethyl acetate and water) using FTIR-ATR method. Additionally, phenolic contents (total phenolics, flavonoids and condensed tannins) and antioxidant activities in vitro (DPPH, FRAP and TAA) were estimated.

\section{Materials and methods}

\section{Chemicals and reagents}

All chemicals used in this study were of analytical grade. Petroleum ether was purchased from Laboratory MAT (Quebec City, QC, Canada) and ethanol was obtained from Alcools de Commerce Inc. (Boucherville, QC, Canada). Ethyl acetate, Folin-Ciocalteu's reagent, anhydrous sodium carbonate $\left(\mathrm{Na}_{2} \mathrm{CO}_{3}\right)$, sodium nitrite $\left(\mathrm{NaNO}_{2}\right)$, hydrochloric acid $(\mathrm{HCl})$, sulfuric acid $\left(\mathrm{H}_{2} \mathrm{SO}_{4}\right)$, vanillin $\left(\mathrm{C}_{8} \mathrm{H}_{8} \mathrm{O}\right)$, iron chloride $\left(\mathrm{FeCl}_{3}\right), 2,4,6$-tripyridyl-1,3,5-triazine (TPTZ), 2,2-diphenyl-1-picrylhydrazyl (DPPH), 6-hydroxy2,5,7,8-tetramethylchroman-2-carboxylic acid (Trolox), gallic acid, quercetin $(95 \%)$, catechin, aluminum chloride $\left(\mathrm{Al}_{2} \mathrm{Cl}_{3} \cdot 6 \mathrm{H}_{2} \mathrm{O}\right)$, sodium hydroxides $(\mathrm{NaOH})$, sodium phosphate and ammonium molybdate were purchased from Sigma-Aldrich Canada Ltd (Oakville, ON, Canada).

Standards of the following phenolic acids and flavonoids are available commercially and used in the present work: (+)- catechin, eriodictyol, $p$-coumaric acid, caffeic acid, luteolin, diosmin and isorhamnetin were purchased from Sigma-Aldrich Chemical Co. (St. Louis, MO, USA); syringic acid chlorogenic acid, gallic acid, $p$-hydroxy benzoic acid, vanillic acid, ferulic acid, rutin, apigenin-7-o- glucoside and apigenin were purchased from Tokyo Chemical Industry Co. (Tokyo, Japan). The solvents used for chromatography were of HPLC grade. The ultrapure water was obtained from a Milli-Q water purification system (Millipore, Bedford, MA, USA).

\section{Plant material and sample preparation}

R. tripartita fruits were collected from Chenini (Gabes, South Tunisia). Fruits were identified by the botanist of the Laboratory of Pastoral Ecosystems and Valorization of Spontaneous Plants, at the "Institut des Regions Arides", Tunisia (IRA). Dried fruits of $R$. tripartita were ground to a fine powder. Extraction was performed using petroleum ether, ethyl acetate, ethanol/water 70/30, v/v and water. First, the samples $(25 \mathrm{~g})$ were mixed with petroleum ether $(250 \mathrm{ml})$ to remove lipophilic compounds. The solvent was removed and the resulting residue was mixed with $70 \%$ ethanol for $24 \mathrm{~h}$ at room temperature $\left(25^{\circ} \mathrm{C}\right)$, to extract the total phenol. The crude extract was then filtered and collected. 
The $70 \%$ aqueous ethanolic extract was further portioned in separating funnel using ethyl acetate for extracting apolar phenolic compounds and water for extracting polar phenolic compounds, yielding extracts and fractions (petroleum ether extract (PEE), 70\% aqueous ethanol extract (AEE), ethyl acetate fraction (EAF) and water fraction (WF)). For checking the biological activity and chemical constituents, complete evaporation of extracts and its partitioned fractions was done using the SpeedVac Automatic Evaporation system (Savant System, Holbrook, NY, USA). Each dried extract was weighed and then redissolved in their extracting solvent to a specified volume to obtain known concentrations [21].

\section{Total phenolic content (TPC)}

TPC of the fruit extracts was determined using Folin-Ciocalteu's reagent slightly modified by Dewanto et al. [22] using gallic acid as a standard. Briefly, $125 \mu \mathrm{L}$ of suitable diluted sample was added to $500 \mu \mathrm{L}$ of distilled water and $125 \mu \mathrm{L}$ of the Folin-Ciocalteu's reagent. The mixture was shaken and allowed to stand for $6 \mathrm{~min}$, before addition of $1250 \mu \mathrm{L}$ of $\mathrm{Na}_{2} \mathrm{CO}_{3}(70 \%)$. The solution was then adjusted with distilled water to a final volume of $3 \mathrm{ml}$. The absorbance of the resulting solution was measured at $760 \mathrm{~nm}$ by UV spectroscopy, after incubation for $90 \mathrm{~min}$. TPC of $R$. tripartita fruits was expressed as milligrams of gallic acid equivalents/g of dry weight (mg GAE/g DW) through the calibration curve with known concentration of gallic acid.

\section{Total flavonoid content (TFC)}

TFC was measured using a colorimetric assay developed by Dewanto et al. [22]. An aliquot of diluted sample or standard solution of quercetin was added to $75 \mu \mathrm{l}$ of sodium nitrite solution $\left(\mathrm{NaNO}_{2}, 7 \%\right)$, and mixed for 6 min before adding $150 \mu \mathrm{l}$ of $\mathrm{AlCl}_{3}, 6 \mathrm{H}_{2} \mathrm{O}(10 \%)$. After $5 \mathrm{~min}, 0.5 \mathrm{ml}$ of $1 \mathrm{M} \mathrm{NaOH}$ solution was added. The final volume was adjusted to $2.5 \mathrm{ml}$ with distilled water and thoroughly mixed. The absorbance of the mixture was determined at $510 \mathrm{~nm}$ by UV Spectoscopy. TFC was determined by a quercetin standard curve and values were expressed as mg quercetin equivalent/g of dry weight (mg QE/g DW).

\section{Total condensed tannin content (CTC)}

CTC (of proanthocyanidins) was determined by using the modified vanillin assay described by Sun et al. [23]. Three milliliters of $4 \%$ ethanol vanillin solution and $1.5 \mathrm{~mL}$ of concentrated $\mathrm{H}_{2} \mathrm{SO}_{4}$ were added to $50 \mu \mathrm{l}$ of suitably diluted sample. The mixture was allowed to stand for $15 \mathrm{~min}$, and the absorbance was measured at $500 \mathrm{~nm}$ by UV spectroscopy against solvent as a blank. Total condensed tannin content was expressed as milligrams of catechin equivalent/g of dry weight (mg CE/g DW), through the calibration curve of catechin. All samples were analyzed in triplicate.

\section{Antiradical-scavenging activity}

These antioxidant activities of the R.tripartita extracts and fractions were measured in terms of hydrogen-donating or radical-scavenging ability using the DPPH method [24]. A sample of $25 \mu \mathrm{L}$ of each extract or fraction was added to $1 \mathrm{ml}$ of a $4 \times 10^{-5} \mathrm{M}$ DPPH methanolic solution. The mixture was placed in the dark at room temperature for $60 \mathrm{~min}$. The absorbance of the resulting solution was measured at $517 \mathrm{~nm}$. The results were expressed as milligram Trolox equivalents (TE) per gram of sample dry weight (mg TE/g DW).

\section{Ferric-reducing antioxidant potential (FRAP)}

FRAP assay was determined in each fraction extract according to Benzie and Strain [25] with a few minor modifications. The method is based on the ability of the sample to reduce $\mathrm{Fe}^{+}$to $\mathrm{Fe}^{2+}$ ions. In the presence of TPTZ, the $\mathrm{Fe}^{2+}-\mathrm{TPTZ}$ complex exhibits blue color at $593 \mathrm{~nm}$ in the UV-visible range. The FRAP reagent was prepared by mixing 10 volume of $300 \mathrm{mM}$ acetate buffer, 1 volume of $10 \mathrm{mM}$ TPTZ in $40 \mathrm{mM} \mathrm{HCl}$ and 1 volume of $20 \mathrm{mM} \mathrm{FeCl}_{3} .200 \mu \mathrm{L}$ of the sample was added to $2800 \mu \mathrm{L}$ of freshly prepared FRAP reagents. The mixture was incubated at $37^{\circ} \mathrm{C}$ throughout the reaction. The antioxidant potential of the fraction extracts was determined based on a calibration curve plotted using Trolox as standard. All samples were analyzed in triplicate.

\section{Total antioxidant activity (TAA)}

TAA of extracts were evaluated using the phosphomolybdenum method as described by Prieto et al. [26]. An aliquot of $0.2 \mathrm{~mL}$ of fraction extracts was mixed with $2 \mathrm{~mL}$ of the reagent solution ( $0.6 \mathrm{M}$ sulfuric acid, $28 \mathrm{mM}$ sodium phosphate and $4 \mathrm{mM}$ ammonium molybdate). The tubes were capped and incubated in water bath at $95{ }^{\circ} \mathrm{C}$ for $90 \mathrm{~min}$. After the samples were cooled down to room temperature, the absorbance was measured at $695 \mathrm{~nm}$. TAA was determined using a standard curve with ascorbic acid solutions as the reference compound and the reducing capacity of the extracts was expressed as milligrams of ascorbic acid equivalents per gram of sample dry weight (mg AA/g DW).

\section{FTIR-ATR analysis}

Functional groups of Tunisian $R$. tripartita fruits were characterized by Fourier transform infrared with attenuated total reflectance (FTIR-ATR). The analysis was performed using a Spectrum One spectrometer (Perkin-Elmer Instruments, 
Woodbridge, ON, Canada) equipped with an ATR sampling accessory. Spectra were analyzed on a zinc selenide-diamond composite crystal in a range from 4000 to $650 \mathrm{~cm}^{-1}$ with 64 scans recorded at resolution of $4 \mathrm{~cm}^{-1}$. Background was collected under identical conditions to the sample and then subtracted from the sample spectra by using the software Spectrum.

\section{LC-ESI-MS/MS analysis}

One gram of each freeze-dried extract (70\% AEE)/fraction (EAF) was dissolved in methanol. The sample was passed through a $0.45 \mu \mathrm{m}$ nylon filter before injection into the LC-ESI-MS/MS. An Agilent Technologies 1260 Infinity liquid chromatography system equipped with a vacuum degasser (G1322A, USA), a quaternary pump (G13311A, USA), a column compartment (G1316A, USA), a diode-array detector (G1315D, USA) and an autosampler (G1329A, USA) connected to a triple-quadrupole mass spectrometer (Agilent Technologies 6410, U.S.A.) was used to identify the polyphenols found in defatted 70\% AEE and EAF of $R$. tripartita fruits. The specific chromatographic and mass conditions are described below. The HPLC separation was performed on a reversed-phase Zorbax SB-C18 column $(250 \times 4.6 \mathrm{~mm}$ i.d. $5 \mu \mathrm{m}$ particle size, Agilent Technologies, USA) at $25^{\circ} \mathrm{C}$. The mobile phase consisted of $1 \%$ acetic acid in methanol (solvent A) and $1 \%$ acetic acid in water (solvent B) applying the following gradient: 0-6 min: $100-95 \% \mathrm{~B}$, 6-12 min: $95-85 \%$ B, $12-40$ min: $85-0 \%$ B , 40-45 min: 0\% B isocratic, $45-50$ min: 0-100\% B, 50-55 min: 0\% B isocratic. The injection volume was $2 \mu \mathrm{L}$ and the flow rate was $0.4 \mathrm{~mL} \mathrm{~min}^{-1}$. The UV spectra were recorded from 200 to $400 \mathrm{~nm}$. The sample was filtered through a $0.22-\mu \mathrm{m}$ membrane filter before injection. The tandem mass spectrometer was interfaced to the LC system via an ESI source and the interface conditions were as follows: nebulizer pressure of $30 \mathrm{psi}$; a dry gas (N2) flow rate of $10 \mathrm{~L} \mathrm{~min}^{-1}$; and a dry gas temperature of $325^{\circ} \mathrm{C}$. The mass spectrometer was operated in negative ion mode. The ion trap mass spectrometer was operating in the $\mathrm{m} / \mathrm{z}$ 50-2000 mass range. The $\mathrm{MS}^{2}$ spectra were acquired automatically in a data-dependent scan mode that used criteria from the previous MS scan to select the target precursor ion that would be submitted to MS/MS fragmentation. The bioactive compounds were identified mainly by their UV spectra, mass spectra obtained by LC-ESI-MS/ MS and the pseudo-molecular ions by full scan ESI (-)-MS, by comparing with those of authentic standards (when available) and/or those found in the literature for commercial and isolated products.

To realize the quantitative analysis, the multiple reaction mode (MRM) was used. Sixteen phenolic compounds of different groups (hydroxycinnamic acids, hydroxybenzoic acids, flavones, flavonols, flavanones and flavan-3-ols) were quantified in 70\% AEE of $R$. tripartita fruits. For each compound the optimum multiple reaction mode (MRM) conditions were determined (Table 3 ). The calibration curves obtained in MRM mode were used for quantification; peak areas were compared with calibration curves generated by three repeated injections of known standards at seven concentrations $(5-500 \mu \mathrm{g} / \mathrm{L})$. Linearity ranges for calibration curves were determined. The limits of detection (LOD) and quantification (LOQ) for phenolic compounds were determined at signal-to-noise ratios of 3:1 and 10:1 by injecting a series of dilute solutions with known concentrations. Calibration parameters, LOD and LOQ values are in Table 3. The contents of individual phenolics were expressed as milligrams per gram of dry weight $(\mathrm{mg} / \mathrm{g} \mathrm{DW})$. The program MassHunter version B. 03.01 was operated for qualitative analysis and MassHunter version B. 04.00 was used for data acquisition. UV absorption spectra were recorded online during the HPLC analysis.

Standards used in the current experiment were syringic acid, gallic acid, $p$-hydroxy benzoic acid, (+)- catechin, chlorogenic acid, vanillic acid, caffeic acid, $p$-coumaric acid, ferulic acid, rutin, apigenin-7- $O$ - glucoside, eriodictyol, diosmin, luteolin, apigenin and isorhamnetin.

\section{Statistical analysis}

For all the experiments, at least three independent assays were carried and each measurement was performed in triplicate. Analysis of variance (ANOVA) and Duncan's multiple-range tests were used to perform statistical analysis in all results, using IBM SPSS19 Statistics software. Differences between means were considered to be significant when $P \leq 0.05$. The Pearson correlation test was employed to determine the correlation coefficients among phenolic compounds and different antioxidant assays.

\section{Results and discussion}

\section{Phenolic contents}

Phenolic compounds are important dietary antioxidants and have been shown to be more effective antioxidants in vitro than vitamins $\mathrm{E}$ and $\mathrm{C}$ [1]. The extraction of phenolic compounds from a sample is directly related to the compatibility of the compounds with the solvent system [17]. Thus, to observe the effect on fractionation, four different solvents were used to evaluate the TPC, TFC and the TCT present in $R$. tripartita fruits (Table 1). The TPC was significantly different in the above fractions and extracts, viz., PEE, 70\% AEF, EAF and WF $(P \leq 0.001)$. EAF had the highest TPC $(255.00 \pm 2.00 \mathrm{mg}$ GAE/g DW), followed successively by $70 \% \mathrm{AEF}$ and WF $(52.74 \pm 1.42$ and $35.45 \pm 0.41 \mathrm{mg}$ 
Table 1 Total phenolic content, total flavonoid content, condensed tannin content and antioxidant activities of extracts and their fractions in $R$. tripartita fruits

\begin{tabular}{|c|c|c|c|c|c|c|}
\hline Extracts/Fractions & $\begin{array}{l}\text { TPC* (mg GAE/g } \\
\text { DW) }\end{array}$ & $\begin{array}{l}\text { TFC* (mg QE/g } \\
\text { DW) }\end{array}$ & $\begin{array}{l}\mathrm{CTC}^{*}(\mathrm{mg} \mathrm{CT} / \mathrm{g} \\
\text { DW) }\end{array}$ & $\begin{array}{l}\mathrm{DPPH}^{*}(\mathrm{mg} \mathrm{TE} / \mathrm{g} \\
\mathrm{DW})\end{array}$ & $\begin{array}{l}\text { FRAP* (mg TE/g } \\
\text { DW) }\end{array}$ & $\begin{array}{l}\text { TAA* (mg AA/g } \\
\text { DW) }\end{array}$ \\
\hline PEE & $13.22 \pm 0.071^{\mathrm{a}}$ & $12.57 \pm 0.36^{\mathrm{a}}$ & $7.32 \pm 0.57^{\mathrm{a}}$ & $49.55 \pm 1.85^{\mathrm{a}}$ & $5.90 \pm 0.14^{\mathrm{a}}$ & $7.95 \pm 0.13^{\mathrm{a}}$ \\
\hline $70 \% \mathrm{AEE}$ & $52.74 \pm 1.42^{\mathrm{b}}$ & $14.39 \pm 1.17^{\mathrm{b}}$ & $9.18 \pm 0.15^{\mathrm{b}}$ & $96.89 \pm 1.66^{\mathrm{b}}$ & $121.85 \pm 1.36^{\mathrm{b}}$ & $33.07 \pm 0.03^{\mathrm{b}}$ \\
\hline EAF & $255.00 \pm 2.00^{c}$ & $147.00 \pm 1.00^{\mathrm{c}}$ & $9.32 \pm 0.20^{\mathrm{b}}$ & $192.97 \pm 0.36^{\mathrm{c}}$ & $221.95 \pm 2.22^{\mathrm{c}}$ & $43.574 \pm 0.28^{c}$ \\
\hline WF & $35.45 \pm 0.41^{\mathrm{d}}$ & $12.16 \pm 0.15^{\mathrm{a}}$ & $8.35 \pm 0.39^{c}$ & $162.54 \pm 1.73^{\mathrm{d}}$ & $9.401 \pm 0.138^{\mathrm{d}}$ & $16.04 \pm 0.05^{\mathrm{d}}$ \\
\hline
\end{tabular}

*TPC total phenolic content, $* T F C$ total flavonoid content, ${ }^{*} C T C$ condensed tannin content, $* D P P H$ 2,2-diphenyl-1-picrylhydrazyl radical-scavenging activity, ${ }^{*} F R A P$ ferric reducing antioxidant power, ${ }^{*} T A A$ total antioxidant activity

GAE/g DW), respectively), whereas PEE presented the lowest TPC (13.22 $\pm 0.07 \mathrm{mg} \mathrm{GAE} / \mathrm{g} \mathrm{DW})$. Concerning the TFC (Table 1), the obtained results exhibited significant differences in TFC according to the solvent extracting power $(P<0.5)$. The highest amount of TFC was found in EAF $(147.00 \pm 1.00 \mathrm{mg} \mathrm{CE} / \mathrm{g} \mathrm{DW})$, followed by $70 \% \mathrm{AEF}$ $(14.40 \pm 1.17 \mathrm{mg} \mathrm{CE} / \mathrm{g} \mathrm{DW}), \mathrm{PEE}(12.57 \pm 0.36 \mathrm{mg} \mathrm{CE} / \mathrm{g}$ DW) and WF (12.16 $\pm 0.15 \mathrm{mg} \mathrm{CE} / \mathrm{g} \mathrm{DW})$. As shown in Table 1, CTC also varied among different fractions. EAF and $70 \%$ AEF were statistically the richest ones $(9.32 \pm 0.20$ and $9.18 \pm 0.15 \mathrm{mg} \mathrm{CE} / \mathrm{g} \mathrm{DW}$, respectively) as compared to WF and PEE $(8.35 \pm 0.39$ and $7.31 \pm 0.57 \mathrm{mg} \mathrm{CE} / \mathrm{g} \mathrm{DW}$, respectively). These results showed that a higher content of phenolic compounds was obtained in EAF, followed by $70 \%$ AEE. Our findings were supported by previous studies, which reported that extraction solvents significantly affected phenolic contents and EAF exhibited the highest phenolic contents [19]. These results may be due to the variation in the polarities of phenolic compounds, which were selectively more soluble in different solvents [18].

A correlation analysis was performed on the phenolic contents (TPC and TFC) of $R$. tripartita fruit extracts and its fractions using Pearson's method. The correlation between TPC and TFC assay was found to be 0.991 . This indicates that flavonoids are the dominating phenolic group in $R$. tripartita fruits. It was previously noted that some flavonoids were isolated from the aerial parts of $R$. tripartita and flavones are the major flavonoids class found in this fruit [9].

\section{FTIR-ATR screening}

Recently, FTIR-ATR has been applied effectively to estimate the phenolic content and antioxidant capacity of various foods and plant extracts [27]. FTIR-ATR spectra of the different extracts and fractions (PEE, 70\% AEE, EAF and WF) of $R$. tripartita fruits analyzed are shown in Fig. 1a-d. As shown in Fig. 1, according to the solvent extraction, the spectra collected by FTIR differed from each other.

The FTIR-ATR spectrum of PEE (Fig. 1a) is distinctly different from those of $70 \%$ AEE, EAF and WF (Fig. 1b-d). The obvious differences are the hydroxyl peak ranging from
3500 to $3200 \mathrm{~cm}^{-1}$ cannot be seen in it and the peak situated at $1743 \mathrm{~cm}^{-1}$ assigned to the absorption of carbonyl becomes the strongest one, as well as the peaks at 2954, 2924 and $2855 \mathrm{~cm}^{-1}$, which belong to the $\mathrm{CH}$ stretching vibration of methyl and methylene, get stronger. Those characters are the typical absorption of lipophilic components [27]. In addition, some weaker peak of carbonyl at $1708 \mathrm{~cm}^{-1}$ can also be seen in Fig. 1a. The analysis results of GC and HPLC [16] indicated that the fruit of $R$. tripartita is a rich source of lipophilic components. Thus, these notable peaks in Fig. 1a indicate that there are lots of lipophilic components in the petroleum ether extract, such as oil, terpenoids, fatty acids and their esters which contain mostly the functional groups of carbonyl and alkyl.

Analysis of FTIR-ATR spectra (Fig. 1b-d) showed a broad spectrum at 3313,3292 and $3301 \mathrm{~cm}^{-1}$ in $70 \%$ AEE, EAF and W, respectively. It is suggested that observed peak ranging from 3500 to $3200 \mathrm{~cm}^{-1}$, showing the sum of the - $\mathrm{OH}$ stretching derived from different chemical environments, which is characteristic of phenolic extracts [27]. In the region of 2934-2925 $\mathrm{cm}^{-1}$, the $\mathrm{CH}, \mathrm{CH}_{2}$, and $\mathrm{CH}_{3}$ stretching vibrations, derived from carbohydrates and phenolics [28], can be seen in $70 \% \mathrm{EE}, \mathrm{EAF}$ and WF. In the fingerprint region of the samples, an intense peak around $1635.8 \mathrm{~cm}^{-1}$ and $1603 \mathrm{~cm}^{-1}$ was observed in EAF, while the peak at $1647.8 \mathrm{~cm}^{-1}$ in the PEE was too weak to be seen. A medium peak at 1609 and $1606 \mathrm{~cm}^{-1}$ was found in WF and $70 \%$ AEE, respectively. This could be related to $\mathrm{C}=\mathrm{C}$ stretching vibration of aromatic rings and to the vibration of $\mathrm{N}-\mathrm{H}$ of amines, $\mathrm{C}=\mathrm{O}$ of amides and carboxylic groups [29]. Therefore, our results show that the EAF of $R$. tripartita fruits may have higher content of flavonoids and protein. The available literature also revealed the presence of several phytoconstituents, such as flavonoids, biflavonoids and isobiflavonoids in $R$. tripartita fruits [13], which supports our findings. A peak at $1425.9 \mathrm{~cm}^{-1}$ can be seen only in EAF. This peak could be related to $\mathrm{CH}_{3}, \mathrm{CH}_{2}$, flavonoids and aromatic rings, where the vibrations would be the bending $(\delta)$ vibration of $\mathrm{C}-\mathrm{H}$ and the stretching vibration of aromatics [27]. Other stretching that can be identified are $\mathrm{CO}$ and $\mathrm{CH}$ deformations out of plane bonds. The stretching of the 
Fig. 1 Spectra of $R$. tripartita fruits obtained by FTIR-ATR for a petroleum ether extract b $70 \%$ ethanol extract, c ethyl acetate and $\mathbf{d}$ water fractions

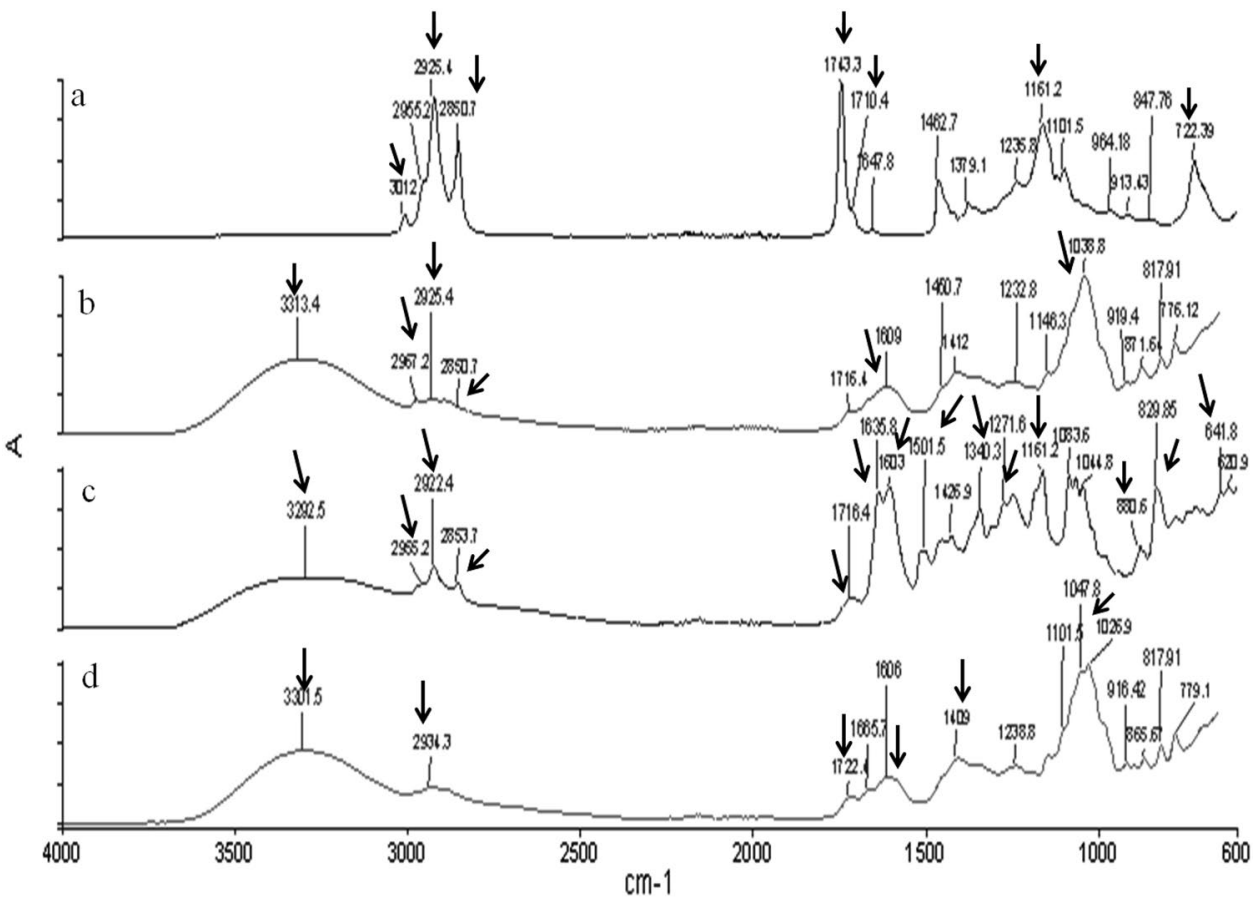

CO bond appears in the region of $1300-1000 \mathrm{~cm}^{-1}$. In this region, the EAF exhibited four signal bands with relatively high intensities $\left(1271,1161,1083\right.$ and $\left.1044 \mathrm{~cm}^{-1}\right)$, and the PEE, 70\% AEE and WF only one (1161, 1036 and 1047, respectively). The vibrations in the regions $923-720 \mathrm{~cm}^{-1}$ are related to $\mathrm{C}-\mathrm{H}$ deformation out of plane, predominantly with signals of low intensities, which corresponds to the carbohydrate [29]. The results obtained in this study suggest that $R$. tripartita fruits contain potentially excellent components with functional properties which can be correlated to its antioxidant activities.

\section{LC-ESI-MS/MS analysis of aqueous ethanol extract and ethyl acetate fraction of $R$. tripartita fruits}

In the present work, a qualitative analysis of the phenolic composition from the 70\% $\mathrm{AEE}$ and EAF of $R$. tripartita fruits was carried out using LC-MS/MS consisting of a triple-quadrupole mass spectrometer equipped with an electrospray ionization (ESI) source. The ESI source at negative ion mode was selected allowing us to obtain high sensitivity. The use of ESI as ionization source operating in the negative mode has proved to be more efficient and sensitive for phenolic compound and flavonoid characterization [30].

$R$. tripartita fruit fractions were analyzed and the HPLC-UV and the LC-ESI-TIC profiles are shown in Fig. 2. In total, 39 compounds were tentatively identified and listed in Table 2 according to their elution order in HPLC-UV chromatograms. The chemical profile was found to be dominated by flavonols, hydroxycinnamic acid and flavones.
Moreover, some hydroxybenzoic acids; flavanones derivatives and flavan3-ols were identified for the first time in $R$. tripartita fruits and largely identified in a great number of Rhus species.

\section{Flavonols $(22,26,27,28,29,30,31$ and 35$)$}

Eight flavonols were identified, on the bases of their online UV and mass spectra in 70\% AEE or EAF, as rutin (peak 23), myricetin (peak 31), quercetin hexose (peak 28), myricetin derivatives (peak 27), isorhamnetin3-O-glucoside (peak 30), myricetin derivatives (peak 29), isorhamnetin (peak 36) and quercetin (peak 32).

Peak $23(\mathrm{R} . \mathrm{T}=25.56 \mathrm{~min})$ exhibited an $[\mathrm{M}-\mathrm{H}]^{-}$parent ion at $\mathrm{m} / \mathrm{z} 609.1$ (aglycone + glucose) and a fragment ion at $\mathrm{m} / \mathrm{z} 300.01$ with UV shape at $\lambda_{\max }$ at $256,356 \mathrm{~nm}$. Compound $\mathbf{2 3}$ was identified as quercetin 3-O-rutinoside (rutin) by comparison of its UV spectrum and mass spectrometric data with an authentic standard. This compound has been recently described in $R$. tripartita fruits [7], $R$. chinensis fruits [31] and R. coriaria L. (Sumac) fruits [32].

Peak 28 eluting at $33.35 \mathrm{~min}$ displayed $[\mathrm{M}-\mathrm{H}]$-parent ion at $\mathrm{m} / \mathrm{z} 463.08$ corresponding to the formula $\mathrm{C}_{21} \mathrm{H}_{20} \mathrm{O}_{12}$. This together with the major $[\mathrm{M}-\mathrm{H}]^{-}$fragment was at $\mathrm{m} / \mathrm{z}$ 300.01 and UV [33]. This compound was not observed previously in $R$. tripartita, but tentatively identified in $R$. coriaria fruits [32].

The MS spectra of peaks $27(\mathrm{RT}=33.21 \mathrm{~min})$ and $\mathbf{2 9}$ $(\mathrm{RT}=33.87 \mathrm{~min})$ with $[\mathrm{M}-\mathrm{H}]^{-}$parent ion $\mathrm{m} / \mathrm{z}$ values at 463.1 and 515.09, respectively, revealed product ions at 
Fig. 2 LC-ESI-MS/MS total ion current (TIC) profiles and HPLC-UV chromatograms monitored at $280 \mathrm{~nm}$ of $R$. tripartita fruits $70 \%$ aqueous ethanol extract (a) and ethyl acetate fraction (c). For peak assignment see Table 2
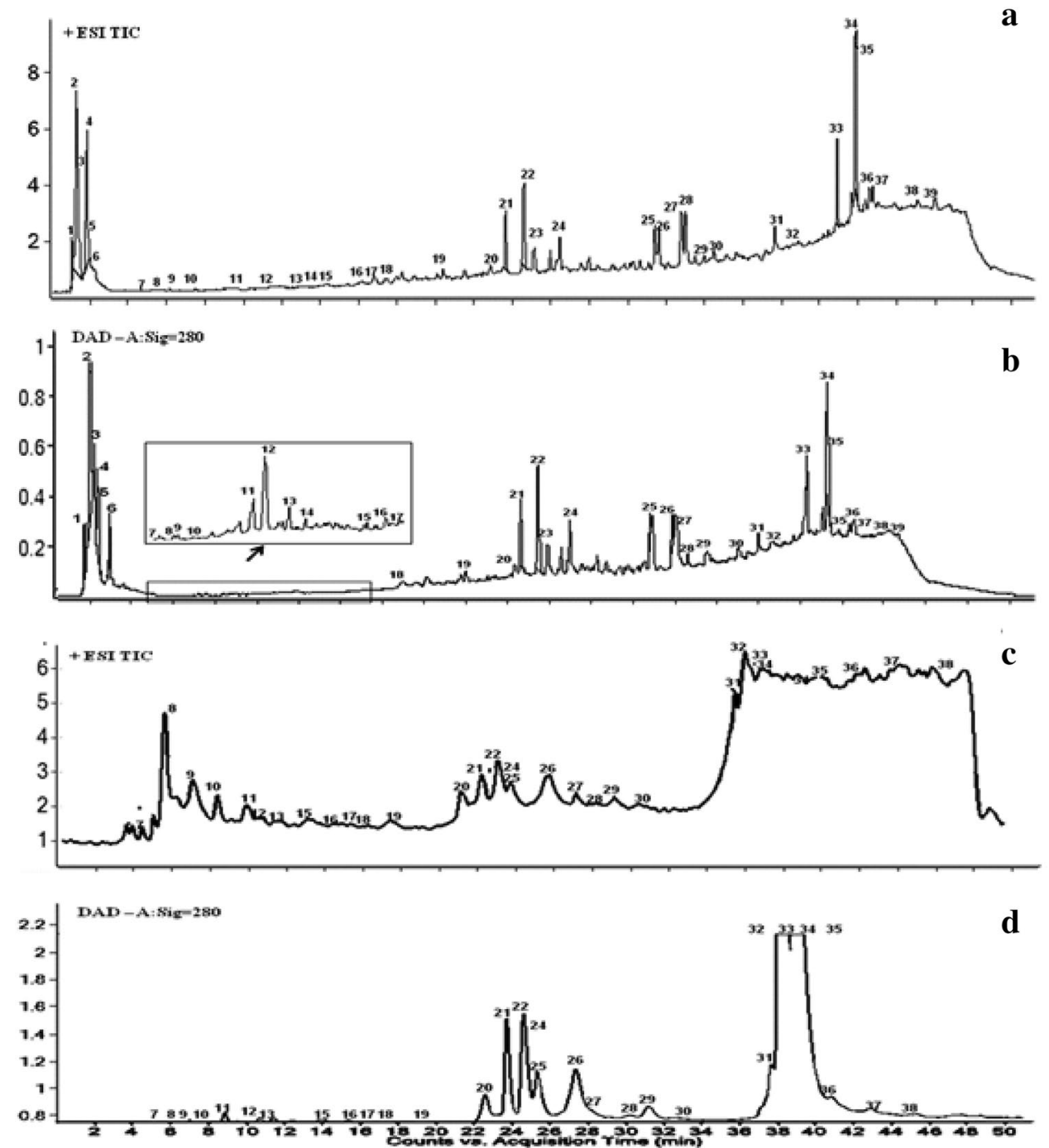

$\mathrm{m} / \mathrm{z} 317.1$ which corresponded to the myricetin moiety. Therefore, they were specifically identified as myricetin derivatives.

Peak 30 (RT $=34.68 \mathrm{~min})$ was proposed to be isorhamnetin-3-O-glucoside because of its $[\mathrm{M}-\mathrm{H}]^{-}$parent ion at $\mathrm{m} / \mathrm{z} 477$, UV shape at $\lambda_{\max }$ at $256,356 \mathrm{~nm}$ and two fragment ions at $\mathrm{m} / \mathrm{z} 314.2$ and 271.1 , which could be interpreted as a loss of a hexose and a $\mathrm{CO}_{2}$ moiety ([M-H-162]- and [M-H-162-44]-).

Myricetin (peak 31, RT=37.91 min) was confirmed by the $[\mathrm{M}-\mathrm{H}]^{-}$parent ion at m/z 317.1 and its MS/MS fragment ions at $\mathrm{m} / \mathrm{z} 179.1$ and 151.1 , while the characteristic peaks of quercetin (peak 32, RT $=38.24 \mathrm{~min}$ ) were found at $\mathrm{m} / \mathrm{z} 301.1,151$ and 179 [32].

The presence of isorhamnetin (peak 36, RT $=42.25 \mathrm{~min}$ ) was identified by a good match of its MS/MS, $\lambda_{\max }$ and retention time with commercial standards. To our best knowledge, this is the first report of isorhamnetin and isorhamnetin-3- $O$-glucoside presence in $R$. tripartita. Myricetin and quercetin were already detected in $R$. tripartita leaves [12].

\section{Flavones $(24,32,33,34$ and 37$)$}

Five flavones were identified, on the bases of their online UV and mass spectra in 70\% AEE and EAF, as luteolin derivatives (peak 25), luteolin (peak 33) apigenin-7-o-glucoside (peak 34), apigenin (peak 35) and diosmin (peak 38) with $[\mathrm{M}-\mathrm{H}]^{-}$parent ion $\mathrm{m} / \mathrm{z}$ values of $447.1,284.9,431.2,269.1$ and 607 , respectively.

The identification of Peak 25 eluting at $31.77 \mathrm{~min}$ in $\mathrm{EF}$ and EAF was based in its fragments ion at $\mathrm{m} / \mathrm{z} 284.9$, which correspond to the luteolin moiety. Presenting the typical UV spectrum of luteolin, the compound $\mathbf{2 5}$ was tentatively identified as luteolin-7-O-glucoside. This compound was earlier reported in Rhus chinensis fruits [31]. 
Table 2 Phenolic compounds identified in R. tripartita fruits extract (70\% AEE) and fraction (EAF) by LC-ESI-MS and LC-ESI-MS/MS analysis

\begin{tabular}{|c|c|c|c|c|c|c|c|c|}
\hline$N$ & $R_{t}[\min ]$ & Molecular formula & {$\left[\mathrm{M}-\mathrm{H}^{-}\right]$} & Major fragments ions & $\lambda_{\max }$ & Compound & Fractions & References \\
\hline 1 & 1.69 & $\mathrm{C}_{20} \mathrm{H}_{24} \mathrm{O}_{14}$ & 487.05 & 341,179 & $250,297,324$ & Caffeic acid derivatives & $70 \%$ AEE, EAF & {$[30]$} \\
\hline 2 & 1.82 & $\mathrm{C}_{6} \mathrm{H}_{12} \mathrm{O}_{7}$ & 195.01 & - & 280 & Galactonic acid & $70 \% \mathrm{AEE}$ & {$[6]$} \\
\hline 3 & 1.84 & $\mathrm{C}_{6} \mathrm{H}_{8} \mathrm{O}_{7}$ & 191.01 & 173.01 & 280 & Quinic acid & $70 \%$ AEE & {$[32]$} \\
\hline 4 & 2.08 & $\mathrm{C}_{7} \mathrm{H}_{12} \mathrm{O}_{6}$ & 191 & 127 & 280 & Citric acid & $70 \%$ AEE & {$[31]$} \\
\hline 5 & 2.44 & $\mathrm{C}_{4} \mathrm{H}_{6} \mathrm{O}_{5}$ & 133 & 115 & 280 & Malic acid & $70 \%$ AEE & {$[32]$} \\
\hline 6 & 3.24 & $\mathrm{C}_{7} \mathrm{H}_{6} \mathrm{O}_{5}$ & 169 & 125 & 272 & Gallic acid & $70 \%$ AEE, EAF & Standard \\
\hline 7 & 5.37 & $\mathrm{C}_{15} \mathrm{H}_{14} \mathrm{O}_{6}$ & 289 & 245 & 279 & (+) Catechin & $70 \%$ AEE, EAF & Standard \\
\hline 8 & 5.91 & $\mathrm{C}_{15} \mathrm{H}_{20} \mathrm{O}_{10}$ & 403 & 241,197 & 276 & Syringic acid derivatives & $70 \%$ AEE, EAF & {$[30]$} \\
\hline 9 & 6.31 & C15H17O9 & 341 & 179,135 & $250,297,324$ & Caffeic acid glucoside & $70 \%$ AEE, EAF & [3] \\
\hline 10 & 7.21 & $\mathrm{C}_{16} \mathrm{H}_{19} \mathrm{O}_{9}$ & 355 & 193 & 250,323 & Ferulic acid derivatives & $70 \%$ AEE, EAF & {$[32]$} \\
\hline 11 & 9.72 & $\mathrm{C}_{20} \mathrm{H}_{20} \mathrm{O}_{14}$ & 483 & 169,125 & $250,272,324$ & Di-galloyl-glucose & $70 \%$ AEE, EAF & {$[32]$} \\
\hline 12 & 11.68 & $\mathrm{C}_{15} \mathrm{H}_{14} \mathrm{O}_{6}$ & 289 & 244.5 & 278 & Epicatechin & $70 \%$ AEE, EAF & [18] \\
\hline 13 & 12.72 & $\mathrm{C}_{7} \mathrm{H}_{6} \mathrm{O}_{3}$ & 137 & 93 & 280,325 & $\begin{array}{l}\text { p-hydroxy benzoic acid } \\
\text { isomer } 1\end{array}$ & $70 \%$ AEE, EAF & Standard \\
\hline 14 & 13.52 & $\mathrm{C}_{16} \mathrm{H}_{18} \mathrm{O}_{9}$ & 353 & 191 & $250,297,325$ & Chlorogenic acid & $70 \%$ AEE & Standard \\
\hline 15 & 14.90 & $\mathrm{C}_{7} \mathrm{H}_{6} \mathrm{O}_{3}$ & 137 & 93 & $250,297,325$ & $\begin{array}{l}\text { p-hydroxy benzoic acid } \\
\text { isomer } 2\end{array}$ & $70 \%$ AEE, EAF & {$[18]$} \\
\hline 16 & 16.03 & $\mathrm{C}_{8} \mathrm{H}_{8} \mathrm{O}_{4}$ & 167 & 123 & 280 & Vanillic acid & $70 \%$ AEE, EAF & Standard, \\
\hline 17 & 16.24 & $\mathrm{C}_{9} \mathrm{H}_{8} \mathrm{O}_{4}$ & 179 & 134 & $250,297,324$ & Caffeic acid & $70 \%$ AEE, EAF & Standard, \\
\hline 18 & 17.74 & $\mathrm{C}_{9} \mathrm{H}_{10} \mathrm{O}_{5}$ & 197 & 153 & 274 & Syringic acid & $70 \%$ AEE, EAF & Standard, \\
\hline 19 & 20.23 & $\mathrm{C}_{15} \mathrm{H}_{20} \mathrm{O}_{10}$ & 359. & 197 & 274 & Syringic acid derivatives & $70 \%$ AEE, EAF & {$[32]$} \\
\hline 20 & 23.70 & $\mathrm{C}_{9} \mathrm{H}_{8} \mathrm{O}_{3}$ & 163 & 119 & 236,310 & p-coumaric acid & $70 \%$ AEE, EAF & Standard, \\
\hline 21 & 23.90 & $\mathrm{C}_{10} \mathrm{H}_{10} \mathrm{O}_{4}$ & 193 & 134.1 & 250,323 & Ferulic acid & $70 \%$ AEE, EAF & Standard, \\
\hline 22 & 24.86 & $\mathrm{C}_{21} \mathrm{H}_{22} \mathrm{O}_{11}$ & 449 & 287 & $250,275,355$ & Eriodictyol derivatives & $70 \%$ AEE, EAF & {$[32]$} \\
\hline 23 & 25.56 & $\mathrm{C}_{27} \mathrm{H}_{30} \mathrm{O}_{16}$ & 609 & 301.2 & $255 ; 356$ & Rutin & $70 \%$ AEE, & Standard \\
\hline 24 & 26.38 & $\mathrm{C}_{30} \mathrm{H}_{18} \mathrm{O}_{10}$ & 537 & 375 & 260,341 & Amentoflavones & $70 \%$ AEE, EAF & {$[32]$} \\
\hline 25 & 31.77 & $\mathrm{C}_{21} \mathrm{H}_{20} \mathrm{O}_{11}$ & 447 & 285,248 & 260,365 & Luteolin derivatives: & $70 \%$ AEE, EAF & {$[31]$} \\
\hline 26 & 31.89 & $\mathrm{C}_{21} \mathrm{H}_{22} \mathrm{O}_{11}$ & 449 & 278 & & Eriodictyol derivatives & $70 \%$ AEE, EAF & {$[32]$} \\
\hline 27 & 33.22 & $\mathrm{C}_{21} \mathrm{H}_{20} \mathrm{O}_{13}$ & 463 & 317 & 275 & Myricetin derivatives & $70 \%$ AEE, EAF & {$[31]$} \\
\hline 28 & 33.35 & $\mathrm{C}_{21} \mathrm{H}_{20} \mathrm{O}_{12}$ & 463 & 301 & 279 & Quercétine-3-O-hexose & $70 \%$ AEE, EAF & {$[32]$} \\
\hline 29 & 33.87 & $\mathrm{C}_{23} \mathrm{H}_{16} \mathrm{O}_{14}$ & 515 & 317 & 275 & Myricetin derivatives & $70 \%$ AEE, EAF & {$[32]$} \\
\hline 30 & 34.68 & $\mathrm{C}_{22} \mathrm{H}_{22} \mathrm{O}_{12}$ & 477 & 315 & & Isorhamnetin derivatives & $70 \%$ AEE, EAF & {$[32]$} \\
\hline 31 & 37.91 & $\mathrm{C}_{15} \mathrm{H}_{10} \mathrm{O}_{8}$ & 317 & 151 & 276 & Myricetin & $70 \%$ AEE, EAF & Standard, \\
\hline 32 & 38.24 & $\mathrm{C}_{15} \mathrm{H}_{10} \mathrm{O}_{7}$ & 301.03 & 151 & 279 & Quercetin & $70 \%$ AEE, EAF & {$[12]$} \\
\hline 33 & 41.02 & $\mathrm{C}_{15} \mathrm{H}_{10} \mathrm{O}_{6}$ & 284.9 & 133 & 260,365 & Luteolin & $70 \%$ AEE, EAF & Standard \\
\hline 34 & 42.01 & $\mathrm{C}_{21} \mathrm{H}_{20} \mathrm{O}_{10}$ & 431 & 269.1 & 272,335 & Apigenin 7-0-glucoside & $70 \%$ AEE, EAF & Standard \\
\hline 35 & 41.95 & $\mathrm{C}_{15} \mathrm{H}_{10} \mathrm{O}_{5}$ & 268.9 & 116.9 & 272,335 & Apigenin & $70 \%$ AEE, EAF & Standard \\
\hline 36 & 42.19 & $\mathrm{C}_{16} \mathrm{H}_{12} \mathrm{O}_{7}$ & 315 & 300 & 150 & Isorhamnetin & $70 \%$ AEE, EAF & Standard \\
\hline 37 & 42.29 & $\mathrm{C}_{15} \mathrm{H}_{12} \mathrm{O}_{6}$ & 287 & 151 & 220 & Eriodictyol & $70 \%$ AEE, EAF & Standard \\
\hline 38 & 45.59 & $\mathrm{C}_{28} \mathrm{H}_{32} \mathrm{O}_{15}$ & 609 & 463 & 150 & Diosmin & $70 \%$ AEE, EAF & Standard \\
\hline 39 & 45.90 & $\mathrm{C}_{30} \mathrm{H}_{48} \mathrm{O}_{3}$ & 455 & - & & Betulinic acid & $70 \%$ AEE & {$[32]$} \\
\hline
\end{tabular}

The compounds $33, \mathbf{3 4}, \mathbf{3 5}$ and $\mathbf{3 8}$ were positively identified as luteolin, apigenin-7-o-glucoside, apigenin and diosmin, respectively, by comparing RT, UV and $\mathrm{MS}^{2}$ fragmentations with those of authentic standards. Some of these compounds (apigenin and luteolin) have been noted in Rhus species [34], but for the first time in R. tripartita.

\section{Flavan-3-ols (7 and 12)}

Peaks 7 and $\mathbf{1 2}$ eluting at $5.36 \mathrm{~min}$ and $11.62 \mathrm{~min}$ in EF and EAF, respectively, had the same $[\mathrm{M}-\mathrm{H}]^{-}$parent ion at $\mathrm{m} / \mathrm{z}$ 289 , belonging to the flavan-3-ol group. Their fragmentation spectra were specifically dominated by the fragments 
Table 3 Phenolic compounds identified in $R$. tripartita fruits (70\% AEE) by LC-ESI-MS/MS, including: quantitative transition $(m / z)$, fragmentor $(\mathrm{V})$, collision energy $(\mathrm{V})$, calibration curve, linearity and sensitivity characteristics

\begin{tabular}{|c|c|c|c|c|c|c|c|c|}
\hline Compound & $\begin{array}{l}\text { Quantitative } \\
\text { transition }\end{array}$ & Fragmentor (V) & $\begin{array}{l}\text { Collision } \\
\text { energy } \\
\text { (V) }\end{array}$ & Equation & $R^{2}$ & $\mathrm{LOD}(\mu \mathrm{g} / \mathrm{L})$ & LOQ $(\mu \mathrm{g} / \mathrm{L})$ & $\begin{array}{l}\text { Amount }(\mathrm{mg} / \mathrm{g} \\
\text { DW) }\end{array}$ \\
\hline Gallic acid & $169(125)$ & 100 & 15 & $y=1.9201 x-5356.1$ & 0.9965 & 0.00546 & 0.01822 & $13.41 \pm 0.13$ \\
\hline $\begin{array}{l}\text { Chlorogenic } \\
\text { acid }\end{array}$ & $353(191)$ & 80 & 10 & $y=7.5704 x+37033$ & 0.9959 & 0.00162 & 0.00541 & $0.30 \pm 0.03$ \\
\hline $\begin{array}{l}p \text {-hydroxyben- } \\
\text { zoic acid }\end{array}$ & $137(93)$ & 100 & 10 & $y=0.68217 x+4.1032$ & 0.9998 & 0.00087 & 0.00293 & $4.48 \pm 0.08$ \\
\hline (+) Catechin & $289(245)$ & 135 & 10 & $y=2.6623 x-682.95$ & 0.9999 & 0.00011 & 0.00037 & $6.76 \pm 0.01$ \\
\hline Vanillic acid & $167(123)$ & 80 & 10 & $y=0.37609 x+543.24$ & 0.9988 & 0.00957 & 0.03190 & $1.80 \pm 0.01$ \\
\hline Caffeic acid & $179(135)$ & 100 & 15 & $y=8.4408 x-876.67$ & 0.9997 & 0.00010 & 0.00035 & $2.59 \pm 0.01$ \\
\hline Syringic acid & $197(153)$ & 120 & 10 & $y=0.83081 x+257.55$ & 0.9943 & 0.02058 & 0.06860 & $3.29 \pm 0.03$ \\
\hline$p$-coumaric acid & $163(119)$ & 100 & 15 & $y=0.44132 x+51898$ & 0.9959 & 0.02787 & 0.09290 & $14.28 \pm 0.31$ \\
\hline Ferulic acid & $193(134.1)$ & 80 & 15 & $y=3.9287 x+2821.4$ & 0.9952 & 0.00366 & 0.01221 & $0.17 \pm 0.02$ \\
\hline $\begin{array}{l}\text { Apigenin-7-O- } \\
\text { glucoside }\end{array}$ & $431(269.1)$ & 150 & 25 & $y=6.5494 x-3867.4$ & 0.9999 & 0.00004 & 0.00015 & $30.57 \pm 0.02$ \\
\hline Eriodictyol & $287(151)$ & 100 & 10 & $y=10.373 x+25173$ & 0.9982 & 0.00052 & 0.00173 & $11.78 \pm 0.01$ \\
\hline Rutin & $609(301.2)$ & 220 & 30 & $y=14.080 x-78597$ & 0.9978 & 0.00046 & 0.00156 & $2.70 \pm 0.02$ \\
\hline Luteolin & $284.9(133)$ & 150 & 30 & $y=11.199 x+30081$ & 0.9951 & 0.00131 & 0.00437 & $10.74 \pm 0.22$ \\
\hline Isorhamnetin & $315(300)$ & 135 & 10 & $y=6.9757 x+4775.8$ & 0.9995 & 0.00021 & 0.00071 & $0.17 \pm 0.01$ \\
\hline Apigenin & $268.9(116.9)$ & 150 & 40 & $y=12,418 x+20,151$ & 0,9986 & 0.00033 & 0.00112 & $20.87 \pm 0.12$ \\
\hline Diosmin & $607(461)$ & 150 & 25 & $y=11.6472 x+125.8$ & 0.9914 & 0.00221 & 0.00738 & $0.77 \pm 0.03$ \\
\hline
\end{tabular}

ions at $\mathrm{m} / \mathrm{z} 245.2$ and 244.8 , corresponding to the loss of $\mathrm{CO}_{2}$ moieties $\left([\mathrm{M}-\mathrm{H}-44]^{-}\right)$. The UV spectra of peaks 7 and 12 presented UV shape with $\lambda_{\max }$ at $279 \mathrm{~nm}$ characteristic of flavanols. Flavan-3-ols typically exhibit an intense band II (275-285 nm) and do not present band I at region $350-370 \mathrm{~nm}$ as a result of their lacking any conjugation between the A and B ring [21]. Since compound 7 was positively identified as catechin using an authentic standard, compound $\mathbf{1 2}$ is likely epicatechin [31]. These compounds were identified by LC-ESI-MS/MS, and reported as active compounds in Amygdalus communis [1]. Catechin was previously identified in $R$. tripartita fruits [7]. This is the first report on the presence of epicatechin in $R$. tripartita.

\section{Flavanones $(22,26$ and 37$)$}

Compound 37 (RT $=42.32 \mathrm{~min})$ was positively identified as eriodictyol by comparing with the authentic standard. The MS spectra of peaks $22(\mathrm{RT}=24.86 \mathrm{~min})$ and $\mathbf{2 6}$ $(\mathrm{RT}=31.89 \mathrm{~min})$ with $[\mathrm{M}-\mathrm{H}]^{-}$parent ion at $\mathrm{m} / \mathrm{z} 449$, revealed fragment ions at $\mathrm{m} / \mathrm{z} 287$ which corresponded to the eriodictyol moiety. Therefore, they were specifically identified as eriodictyol derivtives. These compounds were previously identified from the fruits of $R$. coriaria [32]. As far as we know, these compounds are reported herein in $R$. tripartita for the first time.

\section{Hydroxycinnamic acids $(1,9,10,17,20$ and 21)}

For the hydroxycinnamic acid derivatives, three of phenolics were unambiguously identified by comparing RT and UV spectra, and further confirmed with MS spectral data of standards. An additional three compounds were tentatively identified on the basis of MS/MS fragmentations, UV spectra and other information available in the literature.

Compounds 17, 20 and 21 were identified as caffeic acid, $p$-coumaric acid and ferulic acid, respectively, as the RTs and MS/MS fragments were identical with their authentic standards. These compounds were determined in this species for the first time.

Compounds $1(\mathrm{RT}=1.69 \mathrm{~min})$ and $\mathbf{9}(\mathrm{RT}=6.20 \mathrm{~min})$ displayed $[\mathrm{M}-\mathrm{H}]^{-}$parent ion at $\mathrm{m} / \mathrm{z} 487.05$ and 34.1 , respectively. Both mass spectra yielded the same fragmentation pattern as caffeic acid (the same $\mathrm{m} / \mathrm{z}$ value as the deprotonated molecular ion of caffeic acid), therefore suggesting that they could be their derivatives. The same fragments had previously been reported for caffeic acid hexoside [3, 30]. Compound $10(\mathrm{RT}=7.41)$ showed the $[\mathrm{M}-\mathrm{H}]^{-}$parent ion at $\mathrm{m} / \mathrm{z} 355$ corresponding to the formula $\mathrm{C}_{16} \mathrm{H}_{19} \mathrm{O}_{9}$. This together with the major $[\mathrm{M}-\mathrm{H}]^{-}$fragment at $\mathrm{m} / \mathrm{z}$ and UV shape at $\lambda_{\max }$ at $\mathrm{nm}$ allowed to identify this compound as ferulic acid derivative [30]. 
Hydroxybenzoic acids $(6,8,13,14,15,16,18$ and 19)

Different hydroxybenzoic acid derivatives were detected in R.tripartita fruits. Compounds 6, 13, 14, 16 and 18 were positively identified as gallic acid, $p$-hydroxybenzoic acid, chlorogenic acid, vanillic acid and syringic acid, respectively, by comparing RTs and UV spectra, and further confirmed with MS spectral data of standards. These compounds (without vanillic acid) had also been reported in leaves, stems [11], roots [20] and fruits of $R$. tripartita [7]. Although vanillic acid has been previously reported in $R$. typhina [34], this is the first report on the presence of vanillic acid in $R$. tripartita.

The identification of peak 15 eluting at $14.90 \mathrm{~min}$ in EAF was based in its fragments ion at $\mathrm{m} / \mathrm{z} 137$, which correspond to the $p$-hydroxybenzoic acid. Presenting the typical UV spectrum of $p$-hydroxybenzoic acid, the compound 24 was tentatively identified as $p$-hydroxybenzoic acid isomer.

The MS spectra of peaks $8(\mathrm{RT}=5.89 \mathrm{~min})$ and $\mathbf{1 9}$ $\left(\mathrm{RT}=20.24 \mathrm{~min}\right.$ ) displayed the $[\mathrm{M}-\mathrm{H}]^{-}$parent ion $\mathrm{m} / \mathrm{z}$ values at 403 and 359, respectively. Both mass spectra yielded the same fragmentation pattern as syringic acid. Therefore, they were specifically identified as syringic acid derivatives. These compounds were recently identified in $R$. coriaria fruits [32]. Nevertheless, it is reported here for the first time in R. tripartita.

\section{Organic acids $(2,3,4$ and 5$)$}

Several organic acids were tentatively identified in only EF of $R$. tripartita fruits and have been detected, in accordance with the literature. Compound $2(\mathrm{RT}=1.82 \mathrm{~min})$ gave molecular ion $[\mathrm{M}-\mathrm{H}]^{-}$with $\mathrm{m} / \mathrm{z} 195.0510$ corresponding to the molecular formula $\mathrm{C}_{6} \mathrm{H}_{12} \mathrm{O}_{7}$. It was identified as galactonic acid by its mass spectrometric data and literature; in fact, it was recently determined in $R$. tripartita leaves and stems by Ref. [6].

Compound $3(\mathrm{Rt}=1.86 \mathrm{~min})$ exhibited a deprotonated molecular ions $[\mathrm{M}-\mathrm{H}]^{-}$at $\mathrm{m} / \mathrm{z} 191$ corresponding to the formula $\mathrm{C}_{6} \mathrm{H}_{8} \mathrm{O}_{7}$. This together with the major $[\mathrm{M}-\mathrm{H}]^{-}$fragment at $\mathrm{m} / \mathrm{z}$ allowed to identify this compound as quinic acid [6].

Compound $4(\mathrm{Rt}=2.08 \mathrm{~min})$ showed a parent ion $[\mathrm{M}-\mathrm{H}]^{-}$at $\mathrm{m} / \mathrm{z} 191$ and MS/MS fragment at $\mathrm{m} / \mathrm{z} 111$ corresponding to $\left[\mathrm{M}-\mathrm{H}-\mathrm{CO}_{2}-2 \mathrm{H}_{2} \mathrm{O}\right]^{-}$. Its fragmentation pattern and UV shape at $\lambda_{\max }$ allowed to identify this compound as citric acid. This compound was determined in cherimoyas, lemons, papayas, passion fruits and strawberries [30], but it was tentatively identified for the first time in $R$. tripartita.

Compound $5(\mathrm{Rt}=2.44 \mathrm{~min})$ showed a deprotonated molecular ion $[\mathrm{M}-\mathrm{H}]^{-}$at $\mathrm{m} / \mathrm{z}, 133$, and fragmentation yielded three prominent fragment ions at $\mathrm{m} / \mathrm{z} 115$ and 71, which can be accounted for by the loss of $\left[\mathrm{M}-\mathrm{HH}_{2} \mathrm{O}\right]^{-}$and
$\left[\mathrm{M}-\mathrm{H}-\mathrm{H}_{2} \mathrm{O}-\mathrm{CO}_{2}\right]^{-}$. Therefore, peak $\mathbf{5}$ was tentatively identified as malic acid. This compound was reported to be the most abundant organic acid in $R$. coriaria [32] and was recently identified in $R$. tripartita leaves and stems [6].

\section{Other compounds}

Other compounds were also characterized in R.tripartita fruits, such as amentoflavone (compound 24), a bioactive which was found in $R$. coriaria fruits [32], but we report it in this work for the first time in this species. Betulinic acid (39) was detected and tentatively characterized in R.tripartita fruits.

\section{Quantification of individual phenolic compounds}

To identify the individual phenolic compounds, a liquid chromatography-electrospray-tandem mass spectrometry analysis was utilized in this study. The selectivity was assessed through the use of MRM following the chromatographic separation. This is the most sensitive mode and provides the best specificity for a given analyte [35]. All calibration curves were generated from stock standard solutions with three replicates per level. As shown in Table, the correlation coefficients $\left(R^{2}\right)$ of the calibration equations were higher than 0.9914 for all compounds. The limit of detections (LODs) and limit of quantifications (LOQs) were calculated using the formula $L O D=3 \mathrm{~s} / \mathrm{S}$ and $L O Q=10 \mathrm{~s} / \mathrm{S}$, where $\mathrm{s}$ is the standard deviation of the response and $\mathrm{S}$ is the slope of the calibration curve. The results indicated that the LOQs for phenolic compounds ranged from 0.0000458 to $0.0278 \mu \mathrm{g} / \mathrm{L}$ (Table 3). According to the LC-MS/MS experiment, the main phenolic acids found in 70\% AEE of $R$. tripartita fruits were $p$-coumaric acid $(14.23 \pm 0.03 \mathrm{mg} / \mathrm{g}$ DW $)$ and gallic acid $(13.65 \mathrm{mg} / \mathrm{g}$ DW). $p$-Hydroxybenzoic acid (4.48), syringic acid (3.30), caffeic acid (2.59) and vanillic $(1.81 \pm 0.03 \mathrm{mg} / \mathrm{g}$ DW) were also highly present in 70\% AEE of $R$. tripartita fruits; whereas low quantities of chlorogenic acid $(0.30 \pm 0.31 \mathrm{mg} / \mathrm{g}$ DW) and ferulic acid $(0.17 \pm 0.01 \mathrm{mg} / \mathrm{g}$ DW) were observed. For the flavonoids, the higher detected compounds were apigenin $-7-O$-glucoside $(36.57 \pm 0.02 \mathrm{mg} / \mathrm{g}$ DW) followed by apigenin $(23.90 \pm 0.12 \mathrm{mg} / \mathrm{g}$ DW $)$, then eriodictyol $(11.78 \pm 0.02 \mathrm{mg} / \mathrm{g} \mathrm{DW})$ and luteolin $(10.74 \pm 0.02 \mathrm{mg} / \mathrm{g} \mathrm{DW})$. Catechin, rutin, diosmin and isorhamnetin were also detected in this extract at a relatively high amount $(6.77 \pm 0.01 \mathrm{mg} / \mathrm{g}$ DW, $2.70 \pm 0.01 \mathrm{mg} / \mathrm{g} \mathrm{DW}$, $0.77 \pm 0.03 \mathrm{mg} / \mathrm{g}$ DW, $0.12 \pm 0.22 \mathrm{mg} / \mathrm{g} \mathrm{DW}$, respectively). Some of the mentioned biomolecules were detected in $R$. tripartita, but many of them were identified and quantified for the first time in this report. Our results clearly showed that apigenin-7-O-glucoside, apigenin, $p$-coumaric acid, gallic acid, eriodictyol and luteolin were the most dominant 
compounds in $R$. tripartita fruits. Interestingly the fruits of $R$. tripartita showed high amounts of apigenin-7- $O$-glucoside and apigenin. Apigenin-7-O-glucoside is considered as one of the most important phenolic compounds having many physiological functions, including antioxidant, anticancer and antibacterial activities [3]. Recently, apigenin has attracted a great interest in the food industry due to the wide range of its biological activities including antioxidant and anti-inflammatory properties [36]. This compound is also found in significant quantities in parsley, celery, chamomile, oranges, thyme, onions, honey and spices [37]. In addition, apigenin was detected in Rhus species such as $R$. typhina, $R$. dentata and $R$. pentheri [38]. Other studies showed that Rhus species are characterized by gallic acid [20]. Our results corroborated those of Ben miled et al. [20] who found high amounts of gallic acid (14.42 mg/g DW) in R. tripartita root cortex extract. This extract showed good antioxidant and hepatoprotective activities in vivo. $p$-coumaric, like many phenolic acids, was shown to possess marked chemoprotectant and antioxidant activities [39].

Overall, this is an innovative study on the phenolic profile of $R$. tripartita fruits. Flavonoids were the predominant compounds in $70 \%$ AEE, although it presented different phenolic profiles, both in terms of phenolic families and contents. The presence of all these promising biomolecules in $R$. tripartita fruits would be of great importance to the food and pharmaceutical industries.

\section{In vitro antioxidant assays analysis}

Currently, there has been increasing interest in the study of antioxidant activity of biomolecules to search bioantioxidants that can be used in pharmaceutical, cosmetic and food industries [1]. In the present study, the antioxidant activities were achieved by three methods (DPPH, FRAP and AAT).

Table 1 illustrates the Trolox equivalent scavenging activity of DPPH obtained for each extract/fraction, and expressed in $\mathrm{mg}$ TE/g DW. The highest radical-scavenging activity was obtained with EAF $(193.00 \pm 0.40 \mathrm{mg}$ TE/g DW), followed by WF (162.00 $\pm 1.70 \mathrm{mg}$ TE/g DW), $70 \%$ AEE $(96.89 \pm 1.66 \mathrm{mg}$ TE/g DW) and PEE $(49.55 \pm 0.89$, $\mathrm{mg}$ TE/g DW). Based on Table 1, the extracts and fractions that possess the highest TPC tend to show stronger DPPH radical-scavenging activity. The differences in DPPH radical-scavenging activity of $R$. tripartita fruits in the current study can be explained by the variation of phenolic groups extracted from different extracts and fractions. In addition, the scavenging ability of phenolic compounds against DPPH radical is closely associated with their chemical structure [19]. The fractions that showed stronger DPPH activity might therefore contain a lot of phenolic compounds that are structurally effective for radical-scavenging activity. This could indicate that the EAF of $R$. tripartita fruits holds not only abandoned flavonoids, but that these compounds function as an active agent in scavenging unpaired DPPH radical. It is well known that flavonoids had an important role in antiradical activity of plant extract [40]. Based on the data above, it can be predicted that many flavonoids class, especially flavones, flavonols and flavanones in EAF of $R$. tripartita fruits, might be responsible for the antiradical properties. Moreover, it is interesting to note that the WF exhibited the second highest radical-scavenging activity. This likely indicates that the substances that excel in reducing the free radical in WF would be mostly hydrophilic molecules.

The results of FRAP presented in Table 1 showed that all extracts and fractions have variable ferric-reducing activity varying from $5.90 \pm 0.14$ to $121.85 \pm 1.40 \mathrm{mg}$ TE/g DW. As shown in Fig. 2b, and as expected, the EAF was able to reduce TPTZ-Fe(III) to TPTZ-Fe(II) in high amounts, whereas the reducing power of PEE was lower than that of the other fractions. 70\% AEE demonstrated the second highest reducing ability. WF showed relatively lower reducing ability considering the higher DPPH radical-scavenging activity in Table 1. Our findings were supported by previous studies, which revealed that EAF was more effective reductant than an extract and other fractions [19].

The results of the total antioxidant activity measured with the phosphomolybdate are presented in Table 1 . The total antioxidant activity of $R$. tripartita fruit extracts and fractions are expressed as equivalents of ascorbic acid $(\mathrm{mg} / \mathrm{g}$ of dry weight). A significant variability between the different extracts and fractions $(P<0.05)$ is observed in Table 1. The EAF showed the highest activity $(43.60 \pm 0.30) \mathrm{mg} \mathrm{AA} / \mathrm{g}$ DW, while PEE displayed the lowest activity $(7.95 \pm 0.13)$ mg AA/g DW. Furthermore, the 70\% AEE and WF presented a moderate activity $(33.07 \pm 0.037$ and $16.04 \pm 0.05 \mathrm{mg}$ $\mathrm{AA} / \mathrm{g}$ DW, respectively). The differences in the effect of solvents on antioxidant activities of $R$. tripartita fruits in the current study can be explained by the variation of phenolic groups extracted by the different solvents. Therefore, in the present study, the promising antioxidant activity of $70 \%$ AEE and EAF might be conferred by phenolic compounds identified through LC-MS/MS analysis, mainly phenolic acids such as gallic acid, $p$-coumaric acid and flavonoids such as luteolin, eriodictyol and apigenin derivatives, which are well known for their antioxidant activity [31].

Correlations between the results of different assays (phenolic contents and antioxidant activities) are shown in Table 4. Significant positive correlations $\left(R^{2}=0.63-0.91\right)$ were observed between the phenolic contents (TPC, TFC and CTC) and values for TAA-, FRAP- and DPPH-scavenging activities of R.tripartita fruits $(P<0.05)$. The highest correlation between the FRAP and the TPC $\left(R^{2}=0.91\right)$ indicate the significant contribution of phenolic to these antioxidant assays. The TAA was closely correlated with the CTC $\left(R^{2}=0.89\right)$. Furthermore, the high correlations 
Table 4 The correlation between phenolic compounds and antioxidant properties of the fruits of $R$. tripartita

\begin{tabular}{|c|c|c|c|c|c|c|c|c|c|c|c|c|}
\hline & \multicolumn{2}{|l|}{ TPC } & \multicolumn{2}{|l|}{ TFC } & \multicolumn{2}{|l|}{ CTC } & \multicolumn{2}{|c|}{ DPPH } & \multicolumn{2}{|c|}{ FRAP } & \multicolumn{2}{|l|}{ TAA } \\
\hline & $r$ & $p$ value & $r$ & $p$ value & $r$ & $p$ value & $r$ & $p$ value & $r$ & $p$ value & $r$ & $p$ value \\
\hline DPPH & 0.069 & $*$ & 0.86 & $* * * *$ & 0.62 & $*$ & - & - & 0.56 & ns & 0.63 & $*$ \\
\hline FRAP & 0.91 & $* * * *$ & 0.74 & $* *$ & 0.79 & $* * *$ & 0.56 & ns & - & - & 0.97 & $* * * *$ \\
\hline AAT & 0.84 & $* * *$ & 0.769 & $* *$ & 0.89 & $* * * *$ & 0.63 & & 0.97 & $* * * *$ & - & - \\
\hline
\end{tabular}

TPC total phenolic content, TFC total flavonoid content, $C T C$ condensed tannin content, DPPH 2,2-diphenyl-1-picrylhydrazyl radical-scavenging activity, FRAP ferric reducing antioxidant power, TAA total antioxidant activity
$\left(R^{2}=0.74-0.86\right)$ between the FRAP- and DPPH-scavenging activity and the TFC enhanced the importance of flavonoids in the antioxidant property of $R$. tripartita fruits. Therefore, in the present study, the promising antioxidant activity of $R$. tripartita fruits might be conferred by phenolic compounds identified through LC-MS/MS analysis. These findings were supported by other studies on $R$. tripartita fruits, which reported that its high antioxidant property was related to richness in flavonoids, especially flavones [8].

Several studies have reported the correlation between the antioxidant activity and the total flavonoid content, which are considered the most representative among the bioactive substances with this activity [40]. Moreover, the antioxidant activity expression is a consequence of the synergism between different phenolic compounds and it cannot be attributed specifically to one constituent [5]. The obtained results also showed that the correlation between DPPHscavenging activity and CTC was relatively low $\left(R^{2}=0.62\right)$, while its correlation with total antioxidant activity was high $\left(R^{2}=0.89\right)$. This suggested that antioxidant components, existing in each fraction, possessed different predominant mechanisms of action. The correlation between DPPHscavenging activity and FRAP was found no significant $\left(R^{2}=0.56 ; P>0.05\right)$. FRAP and DPPH methods had different mechanisms of reaction. The mechanism of DPPH was electron transfer assays and FRAP was the redox assays [18]. Hence, the results of this study showed that DPPH-scavenging activities in different fractions had no linear result with the FRAP capacities.

\section{Conclusions}

The phenolic profile of $R$. tripartita fruits extract and fraction was established for the first time by LC-ESI-MS-MS method. Among the 39 compounds identified, 27 were reported for the first time in this species. Flavonols and hydroxycinnamic acids are the main classes of characterized compounds in AEE and EAF. The major phenolic compounds determined are principally apigenin-7-O-glucoside, apigenin, $p$-coumaric acid, gallic acid, eriodictyol and luteolin in AEE. FTIR-ATR analysis results revealed the presence of characteristic functional groups of phenolic compounds, carboxylic acids, carbohydrates, lipophilic components and proteins in R. tripartita fruits. Furthermore, the results showed that the highest amount of phenolic compounds and the relevant antioxidant activity of extracts and fractions correlate with the phenolic profiles, suggesting that they contain interesting active compounds, essentially flavones, flavonols, flavonones and phenolic acids. These results suggested that $R$. tripartita fruits can be considered as a source of valuable polyphenols for food, cosmetic and pharmaceutical industries.

Acknowledgements The authors would like to express their sincere thanks to Tunisian Ministry of Higher Education and Scientific Research and Carthage University, and special thanks to Research Laboratories in Science, Applied to Food, Canadian Irradiation Centre, INRS-Institut Armand-Frappier for its financial support for conducting this research.

\section{Compliance with ethical standards}

Conflict of interest The authors declare that they have no conflict of interest.

Research involving human and/or animal participants This article does not contain any studies with human participants or animals performed by any of the authors.

\section{References}

1. Tlili N, Kirkan B, Sarikurkcu C (2019) LC-ESI-MS/MS characterization, antioxidant power and inhibitory effects on $\alpha$-amylase and tyrosinase of bioactive compounds from hulls of Amygdalus communis: the influence of the extracting solvents. Ind Crops Prod 128:147-152. https://doi.org/10.1016/j.indcrop.2018.11.014

2. Romagnolo DF, Selmin OI (2012) Flavonoids and cancer prevention: a review of the evidence. J Nutr Gerontol Geriatr 31:206-238

3. Shakeri A et al (2019) LC-ESI/LTQOrbitrap/MS/MS and GCMS profiling of Stachys parviflora L. and evaluation of its biological activities. J Pharm Biomed Anal 168:209-216. https://doi. org/10.1016/j.jpba.2019.02.018

4. Xiang J et al (2019) Profile of phenolic compounds and antioxidant activity of finger millet varieties. Food Chem 275:361-368. https://doi.org/10.1016/j.foodchem.2018.09.120 
5. Tlili N et al (2018) Schinus terebinthifolius vs Schinus molle: a comparative study of the effect of species and location on the phytochemical content of fruits. Ind Crops Prod 122:559-565. https://doi.org/10.1016/j.indcrop.2018.05.080

6. Ben Barka $\mathrm{Z}$ et al (2018) A combination of NMR and liquid chromatography to characterize the protective effects of Rhus tripartita extracts on ethanol-induced toxicity and inflammation on intestinal cells. J Pharm Biomed Anal 150:347-354

7. Tlili N et al (2014) Phytochemicals and antioxidant activities of Rhus tripartitum (Ucria) fruits depending on locality and different stages of maturity. Food Chem 160:98-103. https:// doi.org/10.1016/j.foodchem.2014.03.030

8. Alam P et al (2017) Inter-species comparative antioxidant assay and HPTLC analysis of sakuranetin in the chloroform and ethanol extracts of aerial parts of Rhus retinorrhoea and Rhus tripartita. Pharm Biol 55:1450-1457. https://doi. org/10.1080/13880209.2017.1304428

9. Mahjoub MA et al (2010) Anti-inflammatory and antioxidant activities of some extracts and pure natural products isolated from Rhus tripartitum (Ucria). Med Chem Res 19:271-282

10. Ben Barka Z et al (2016) Evaluation of the anti-diarrheal activity of the hydromethanolic root extract of Rhus tripartita (Ucria) (Anacardiaceae). Biomed Pharmacother Biomed Pharmacother 83:827-834. https://doi.org/10.1016/j.biopha.2016.07.055

11. Ben Barka Z et al (2017) Protective effects of edible Rhus tripartita (Ucria) stem extract against ethanol-induced gastric ulcer in rats. J Funct Foods 30:260-269. https://doi. org/10.1016/j.jff.2017.01.021

12. Mohammed AEI (2015) Phytoconstituents and the study of antioxidant, antimalarial and antimicrobial activities of Rhus tripartita growing in Egypt. J Pharmacogn Phytochem 4: 2762-2781. http://www.phytojournal.com/vol4Issue2/4-3-20.1.html

13. Shahat AA et al (2016) Treatment with Rhus tripartita extract curtails isoproterenol-elicited cardiotoxicity and oxidative stress in rats. BMC Complement Altern Med 16:351

14. Shahat AA, Ibrahim AY, Al-Ghamdi AAM, Alsaid MS (2016) Phytochemical investigation of Rhus tripartita and its activity against cyclooxygenases and acetylcholinesterase. Trop J Pharm Res 15:1697-1706. https://doi.org/10.4314/tjpr.v15i8.15

15. Tlili $\mathrm{N}$ et al (2016) Effects of Rhus tripartitum fruit extract on CCl4-induced hepatotoxicity and cisplatin-induced nephrotoxicity in rats. Can J Physiol Pharmacol 94:801-807

16. Tlili $\mathrm{N}$ et al (2014) Variation in protein and oil content and fatty acid composition of Rhus tripartitum fruits collected at different maturity stages in different locations. Ind Crops Prod 59:197-201. https://doi.org/10.1016/j.indcrop.2014.05.020

17. Pintać D et al (2018) Solvent selection for efficient extraction of bioactive compounds from grape pomace. Ind Crops Prod 111:379-390. https://doi.org/10.1016/j.indcrop.2017.10.038

18. Yang J, Ou X, Zhang X, Zhou Z, Ma L (2017) Effect of different solvents on the measurement of phenolics and the antioxidant activity of Mulberry (Morus atropurpurea Roxb.) with accelerated solvent extraction. J Food Sci 82:605-612

19. Nakamura M, Ra JH, Jee Y, Kim JS (2017) Impact of different partitioned solvents on chemical composition and bioavailability of Sasa quelpaertensis Nakai leaf extract. J Food Drug Anal 25:316-326. https://doi.org/10.1016/j.jfda.2016.08.006

20. Ben Miled H et al (2017) Hepatoprotective activity of Rhus oxyacantha root cortex extract against DDT-induced liver injury in rats. Biomed Pharmacother 90:203-215. https://doi. org/10.1016/j.biopha.2017.03.063

21. Bourgou S et al (2017) LC-ESI-TOF-MS and GC-MS profiling of Artemisia herba-alba and evaluation of its bioactive properties. Food Res Int 99:702-712. https://doi.org/10.1016/j.foodr es.2017.06.009
22. Dewanto V, Wu X, Adom KK, Liu RH (2002) Thermal processing enhances the nutritional value of tomatoes by increasing total antioxidant activity. J Agric Food Chem 50:3010-3014

23. Sun B, Richardo-da-Silvia M, Spranger I (1998) Critical factors of vanillin assay for catechins and proanthocyanidins. J Agric Food Chem 46:4267-4274

24. Fattouch $\mathrm{S}$ et al (2007) Antimicrobial activity of Tunisian quince (Cydonia oblonga Miller) pulp and peel polyphenolic extracts. J Agric Food Chem 55:963-969. https://doi.org/10.1021/jf062614e

25. Benzie IF, Strain JJ (1996) The ferric reducing ability of plasma (FRAP) as a measure of "antioxidant power": the FRAP assay. Anal Biochem 239:70-76. https://doi.org/10.1006/abio.1996.0292

26. Prieto P, Pineda M, Aguilar M (1999) Spectrophotometric quantitation of antioxidant capacity through the formation of a phosphomolybdenum complex: specific application of vitamin E. Anal Biochem 269:337-341

27. Tahir HE et al (2017) Rapid prediction of phenolic compounds and antioxidant activity of Sudanese honey using Raman and Fourier transform infrared (FT-IR) spectroscopy. Food Chem 226:202-211. https://doi.org/10.1016/j.foodchem.2017.01.024

28. Wu Z et al (2016) Comparison between ATR-IR, Raman, concatenated ATR-IR and Raman spectroscopy for the determination of total antioxidant capacity and total phenolic content of Chinese rice wine. Food Chem 194:671-679. https://doi.org/10.1016/j. foodchem.2015.08.071

29. Liu H, Sun S, Lv G, Chan KKC (2006) Study on Angelica and its different extracts by Fourier transform infrared spectroscopy and two-dimensional correlation IR spectroscopy. Spectrochim Acta A Mol Biomol Spectrosc 64:321-326. https://doi.org/10.1016/j. saa.2005.07.026

30. Spínola V, Pinto J, Castilho PC (2015) Identification and quantification of phenolic compounds of selected fruits from Madeira Island by HPLC-DAD-ESI-MSn and screening for their antioxidant activity. Food Chem 173:14-30. https://doi.org/10.1016/j. foodchem.2014.09.163

31. Zhang C, Ma Y, Zhao Y, Hong Y, Cai S, Pang M (2017) Phenolic composition, antioxidant and pancreatic lipase inhibitory activities of Chinese sumac (Rhus chinensis Mill.) fruits extracted by different solvents and interaction between myricetin-3- $O$-rhamnoside and quercetin-3-O-rhamnoside. Int J Food Sci Technol 1-9

32. Abu-Reidah IM et al (2015) HPLC-DAD-ESI-MS/MS screening of bioactive components from Rhus coriaria L. (Sumac) fruits. Food Chem 166:179-191. https://doi.org/10.1016/j.foodc hem.2014.06.011

33. Miceli $\mathrm{N}$ et al (2018) Comparative study of the phenolic profile, antioxidant and antimicrobial activities of leaf extracts of five Juniperus L. (Cupressaceae) taxa growing in Turkey. Nat Prod Res 1-6. https://doi.org/10.1080/14786419.2018.1523162

34. Qiu DR et al (2016) Chemical constituents from the fruits of Rhus typhina $\mathrm{L}$. and their chemotaxonomic significance. Biochem Syst Ecol 69:261-265. https://doi.org/10.1016/j.bse.2016.10.011

35. Sonmezdag AS, Kelebek H, Selli S (2018) Pistachio oil (Pistacia vera L. cv. Uzun): characterization of key odorants in a representative aromatic extract by GC-MS-olfactometry and phenolic profile by LC-ESI-MS/MS. Food Chem 240:24-31. https://doi. org/10.1016/j.foodchem.2017.07.086

36. Abcha I et al (2019) Ethyl oleate food-grade O/W emulsions loaded with apigenin: insights to their formulation characteristics and physico-chemical stability. Food Res Int 116:953-962. https ://doi.org/10.1016/j.foodres.2018.09.032

37. Madunić J et al (2018) Apigenin: a dietary flavonoid with diverse anticancer properties. Cancer Lett 413:11-22. https://doi. org/10.1016/j.canlet.2017.10.041

38. Svenningsen AB et al (2006) Biflavones from Rhus species with affinity for the GABAA/benzodiazepine receptor. J Ethnopharmacol 103:276-280. https://doi.org/10.1016/j.jep.2005.08.012 
39. Bursal E et al (2013) Antioxidant activity and polyphenol content of cherry stem (Cerasus avium L.) determined by LC-MS/ MS. Food Res Int 51:66-74. https://doi.org/10.1016/j.foodr es.2012.11.022

40. Heim KE, Tagliaferro AR, Bobilya DJ (2002) Flavonoid antioxidants: chemistry, metabolism and structure-activity relationships. J Nutr Biochem 13:572-584. https://doi.org/10.1016/S0955 $-2863(02) 00208-5$
Publisher's Note Springer Nature remains neutral with regard to jurisdictional claims in published maps and institutional affiliations. 